\title{
Fuzzy Neural Network Research of Direct Torque Control under Low-speed
}

\author{
Zhang Lian \\ School of Electronic Information and Automation, \\ Chongqing University of Technology \\ Chongqing, China \\ zh_lian@cqut.edu.cn
}

Hu Xiaoqian

School of Electronic Information and Automation, Chongqing University of Technology

Chongqing, China

hxq@cqut.edu.cn

\begin{abstract}
Aiming at the rapid response and speed ripple of direct torque control of asynchronous motor, a fuzzy neural network algorithm based on stator flux model is proposed to achieve the selecting of switch state under low-speed. By using automatic generation of fuzzy neural network algorithm, real-time adjustment of membership function and fuzzy rules, the fuzzy neural network is trained to study network parameters and structure. The simulation results show that the speed control system has desirable dynamic and steady-state performances under the low-speed.
\end{abstract}

Keywords-asynchronous motor; direct torque control; fuzzy control; neural network; simulation

\section{INTRODUCTION}

Direct Torque Control (DTC), because of its advantages of simple control structure, rapid torque response and strong robustness, can to a great extent solve the problems in vector control such as complex structure, large calculation, sensitivity to parameter variation, and etc. The main technical problem of traditional DTC is the large flux and speed ripple. In order to decrease or eliminate the flux and speed ripple under low-speed, to increase speed controlling accuracy, and to enlarge speedadjusting range of DTC system, a fuzzy neural network algorithm is proposed in this paper.

\author{
Tan Yuhang \\ School of Electronic Information and Automation, \\ Chongqing University of Technology \\ Chongqing, China \\ 492612430@qq.com
}

\section{PRINCIPLE OF DIRECT TORQUE CONTROL}

Based on space-vector analysis, the DTC system, takes $3 / 2$ transformation to stator current and voltage by stator flux orientation, directly calculates torque and flux of AC motor under static $\alpha-\beta$ coordinate, and compares them with given torque and flux separately. According to comparison result, the DTC system researches the optimum switch table to generate PWM signal and directly control the switch state of inverter, and the system structure is shown Fig .1.

Under $\alpha-\beta$ coordinate, the flux equation is

$$
\begin{aligned}
& \psi_{s \alpha}=\int\left(u_{s \alpha}-R_{s} i_{s \alpha}\right) d t \\
& \psi_{s \beta}=\int\left(u_{s \beta}-R_{s} i_{s \beta}\right) d t
\end{aligned}
$$

According to stator current and flux, the electromagnetic torque is calculated:

$$
T_{e}=p_{0}\left(i_{s \beta} \times \psi_{s \alpha}-i_{s \alpha} \times \psi_{s \beta}\right)
$$

Where, $s$ and $r$ designate stator and rotor components, $\alpha-\beta$ the axis of two-phase static coordinate, $u_{s \alpha}$ and $u_{s \beta}$ the stator voltage components on $\alpha-\beta$ axis, $i_{s \alpha}$ and $i_{s \beta}$ stator current components on $\alpha-\beta$ axis, $R_{s}$ stator resistance, and $p_{0}$ number of pole pairs.

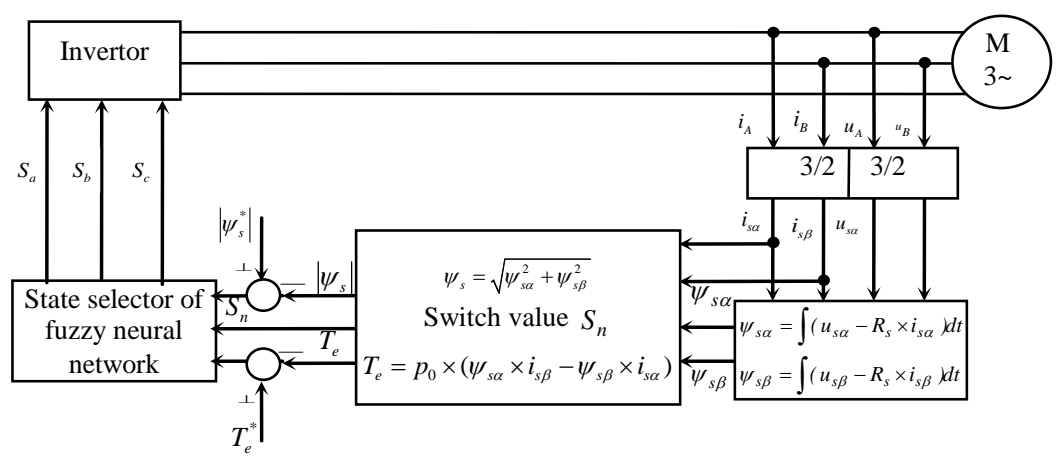

Figure 1. Diagram of control system 


\section{DESIGNING OF FUZZY NEURAL NETWORK CONTROLLER}

The fuzzy neural network is generally consisted of three layers: front layer, middle layer, and rear layer. The front layer fuzzifies input variable, middle layer realizes fuzzy logic inference, and rear layer realizes defuzzification. Each layer is consisted of single-layer or multi-layer nodes, and the node number and weight of every node layer are set by the constructed network, with the needed membership function and fuzzy rules automatically generated by learning algorithm.

This paper applies the five-layer network in Fig .2, including input layer, fuzzification layer, fuzzy inference layer, defuzzification layer and output layer.

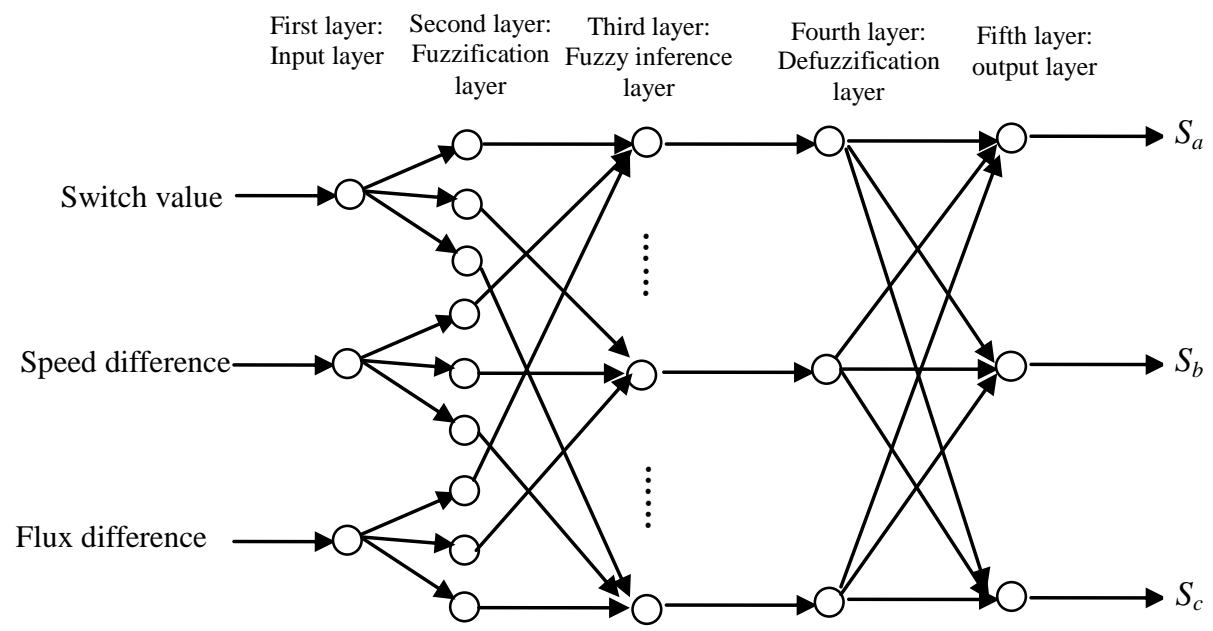

Figure 2. Model of fuzzy neural network

The first layer: input layer. This layer has $N_{1}=3$ nodes, corresponding to switch value, rotational speed difference and flux difference respectively, and with the function to transfer input value $x=\left[x_{1}, x_{2}, x_{3}\right]^{\mathrm{T}}$ to the next layer.

The second layer: fuzzification layer. This layer functions to calculate the membership function $\mu_{i}^{j}$ of each input variable fuzzy set.

$$
\mu_{i}^{j}=\mu_{A_{i}^{j}}\left(x_{i}\right) \quad i=1,2,3 ; j=1,2, \mathrm{~L} m_{i}
$$

Where, $x_{i}$ is input component, and $m_{i}$ is segmentation number of fuzzy grade. All of the 3 input variables are classified as 3 fuzzy grades, i.e. $m_{1}=m_{2}=m_{3}=3$. Then the number of nodes in this layer is $N_{2}=\sum_{i=1}^{3} m_{i}=3 \times 3=9$.

This paper chose Gaussian function as membership function, because of its stable and smooth transient behavior.

$$
\begin{aligned}
\mu_{A_{i}^{j}}\left(x_{i}\right) & =\exp \left[-\left(\frac{x_{i}-c_{i j}}{\sigma_{i j}}\right)^{2}\right] \\
i & =1,2,3 ; j=1,2,3
\end{aligned}
$$

Where, $c_{i j}$ and $\sigma_{i j}$ designate the center and width of Gaussian function, with $i$ the number of input variables and $j$ segmentation number of fuzzy grade of input variable $x_{i}$.

The third layer: fuzzy inference layer. Each node of this layer represents a fuzzy rule in order to match fuzzy rule premise and to calculate fitness value of each fuzzy rule, i.e.

$$
a_{j}=\mu_{1}^{i 1} \mu_{2}^{i 2} \mu_{3}^{i 3}
$$

Where $i_{1} \in\{1,2,3\}, i_{2} \in\{1,2,3\} ， i_{3} \in\{1,2,3\}$, $j=3 \times 3 \times 3=27$ (Each input randomly chooses one as rule number: $\left.C_{3}^{1} \times C_{3}^{1} \times C_{3}^{1}\right)$. The node number of this layer is $N_{3}=j=27$.

The fourth layer: defuzzification layer. The data are normalized in this layer, i.e.

$$
\overline{a_{j}}=a_{j} / \sum_{j=1}^{27} a_{j}, \quad j=1,2, \mathrm{~L} 27
$$

The node number of this layer is equal to that of third layer, i.e. $N_{4}=N_{3}=27$.

The fifth layer: output layer, can output calculation result.

$$
y_{i}=\sum_{j=1}^{27} \omega_{i j} \overline{a_{j}}, \quad i=1,2,3 ; j=1,2, \mathrm{~L} 27
$$

Where, $\omega_{i j}$ is connection weight between the fourth and fifth layers. The node number of this layer is $N_{5}=3$. Therefore, the fuzzy neural network with 3-9-27-27-3 structure is constructed and shown in Fig .2.

The inputs of the controller are space vector, torque difference and flux difference, and the output is the controlled variable of the invertor. The three inputs are defined three fuzzy subsets, and the gaussmf membership function as equation (3) is adopted, which the membership function of each variable and the relative parameters are shown in table I. According to the flux control theory, the 
fuzzy rule shown as table II is built to generate circular stator flux trace.

\section{TABLE I. FUZZY SUBSETS}

\begin{tabular}{|c|c|c|c|c|}
\hline $\begin{array}{l}\text { space } \\
\text { vector }\end{array}$ & $\begin{array}{c}\operatorname{in} 1 \mathrm{mf} 1 \\
\left(\left[\begin{array}{lll}1.062 & 1\end{array}\right]\right)\end{array}$ & $\begin{array}{c}\text { in1mf2 } \\
\text { ([1.062 3.5]) }\end{array}$ & $\begin{array}{c}\text { in1mf3 } \\
([1.0626])\end{array}$ & $\begin{array}{l}\text { range } \\
{\left[\begin{array}{ll}1 & 6\end{array}\right]}\end{array}$ \\
\hline $\begin{array}{c}\text { torque } \\
\text { difference }\end{array}$ & $\begin{array}{c}\text { in2mf1 } \\
([0.21230])\end{array}$ & $\begin{array}{c}\text { in2mf2 } \\
\left(\left[\begin{array}{lll}0.2123 & 0.5\end{array}\right]\right)\end{array}$ & $\begin{array}{c}\operatorname{in} 2 \mathrm{mf} 3 \\
([0.21231])\end{array}$ & $\begin{array}{l}\text { range } \\
{\left[\begin{array}{ll}0 & 1\end{array}\right]}\end{array}$ \\
\hline $\begin{array}{c}\text { flux } \\
\text { difference }\end{array}$ & $\begin{array}{c}\text { in2mf1 } \\
([0.21230])\end{array}$ & $\begin{array}{c}\text { in2mf2 } \\
\left(\left[\begin{array}{lll}0.2123 & 0.5\end{array}\right]\right)\end{array}$ & $\begin{array}{c}\operatorname{in} 2 \mathrm{mf} 3 \\
([0.21231])\end{array}$ & $\begin{array}{r}\text { range } \\
{\left[\begin{array}{ll}0 & 1\end{array}\right]}\end{array}$ \\
\hline
\end{tabular}

TABLE II. FUZZY CONTROL RULE

\begin{tabular}{|c|c|c|c|}
\hline space vector & torque difference & flux difference & output \\
\hline in1mf1 & in2mf1 & in3mf1 & outmf1 \\
\hline in1mf1 & in2mf1 & in3mf2 & outmf2 \\
\hline in1mf1 & in2mf1 & in3mf3 & outmf3 \\
\hline$\ldots$ & $\ldots$ & $\cdots$ & $\cdots$ \\
\hline in1mf3 & in2mf3 & in3mf1 & $\begin{array}{c}\text { outmf2 } \\
5\end{array}$ \\
\hline in1mf3 & in2mf3 & in3mf2 & $\begin{array}{c}\text { outmf } 2 \\
6\end{array}$ \\
\hline in1mf3 & in2mf3 & in3mf3 & $\begin{array}{c}\text { outmf2 } \\
7\end{array}$ \\
\hline
\end{tabular}

Fig .3 gives the error variation and membership degree curves in this fuzzy neural network.

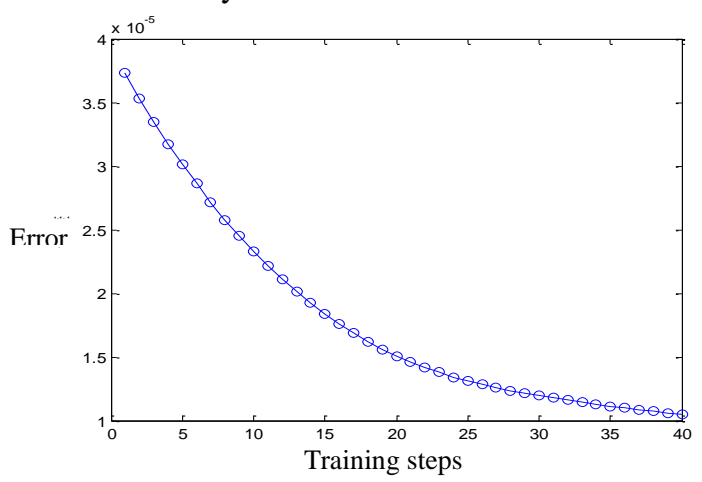

(a) Error training curve
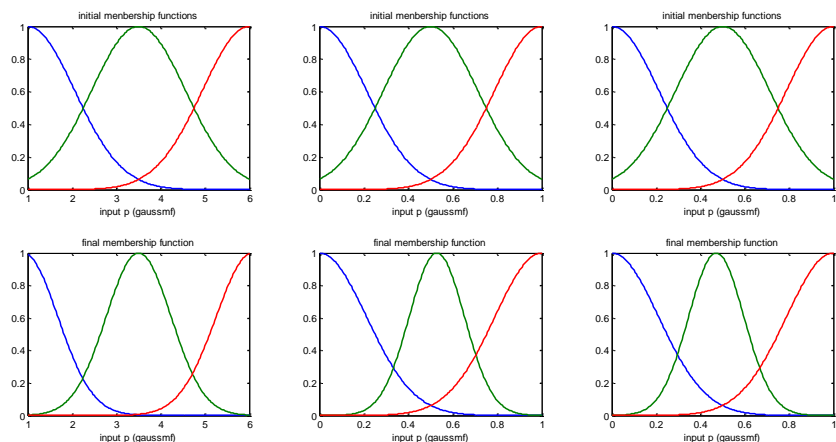

(b) The membership degree function curves before and after training

Figure 3. Curves of error variation and membership degree

The controller based on fuzzy neural network is built as Fig . 4.

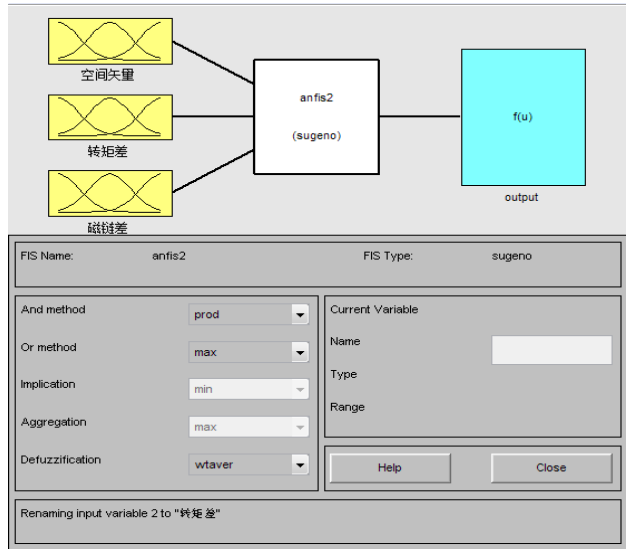

(a) The controller diagram based on fuzzy neural network

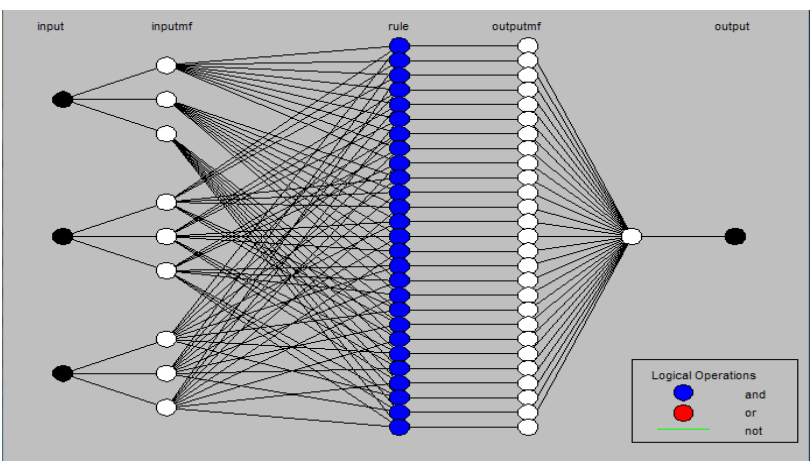

(b) The structure diagram of fuzzy neural network in Matlab Figure 4 . The controller based on fuzzy neural network

\section{SimUlation OF DTC WITH FUZZY NEURAL NETWORK}

The simulation parameters of asynchronous motor are as follows: power $P=3730 \mathrm{~W}$, stator resistance $R_{s}=1.115 \Omega$, rotor resistance $R_{r}=1.083 \Omega$, stator inductance $L_{s}=0.005974 \mathrm{H}$, rotor inductance $L_{r}=0.005974 \mathrm{H} \quad$, mutual inductance $L_{m}=0.2037 \mathrm{H}$, rotational inertia $J=0.02 \mathrm{~kg} \cdot \mathrm{m}^{2}$, dumping factor of motor $R_{\Omega}=0$, number of pole pairs $p_{0}=2$, torque $T_{m}=20 \mathrm{~N} \cdot \mathrm{m}$, rotor speed $n=50 \mathrm{r} / \mathrm{min}, n=1000 \mathrm{r} / \mathrm{min}$. Based on the above parameters, the simulation model of DTC system is shown in Fig .5.

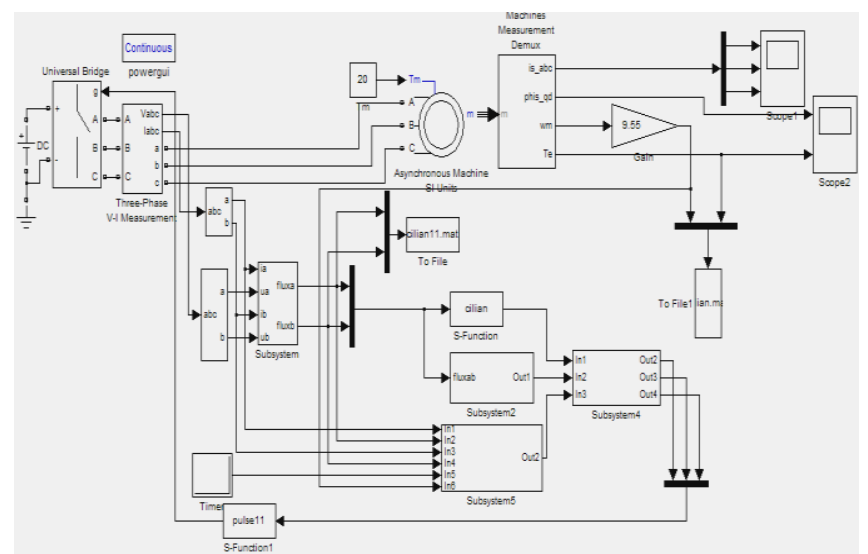

Figure 5. Diagram of system simulation 
The simulation results are shown in Fig .6. It can be concluded that, under low-speed (the given speed: $n=50 \mathrm{r} / \mathrm{min}$ ), the fuzzy neural network has desirable steady-state and dynamic performances with smaller speed ripple and higher stabilization precision.

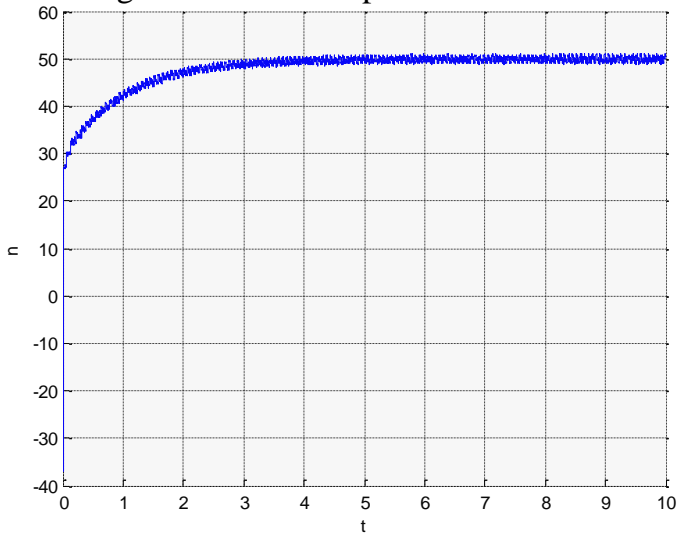

(a)Rotor speed response of fuzzy neural network

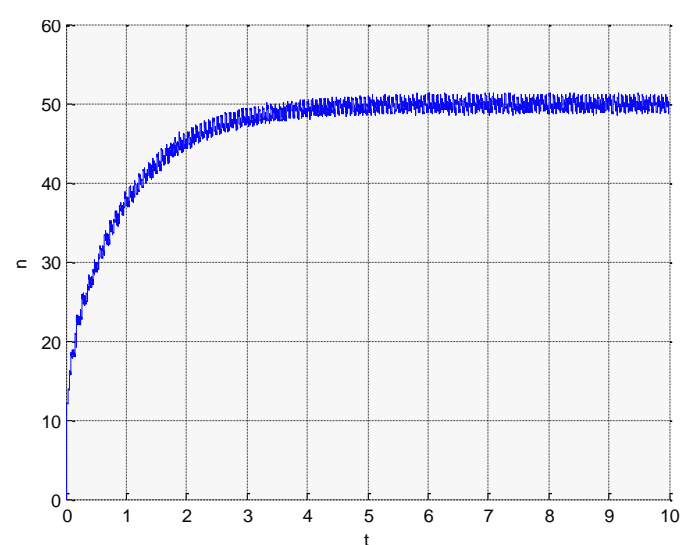

(b) Rotor speed response of traditional DTC

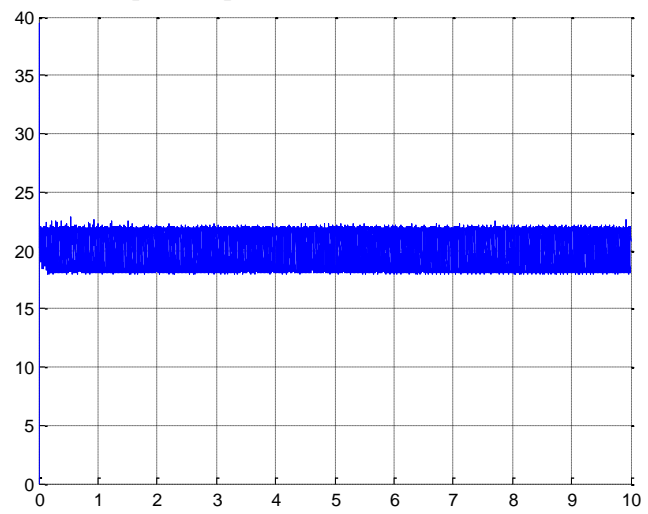

(c) Torque response of fuzzy neural network

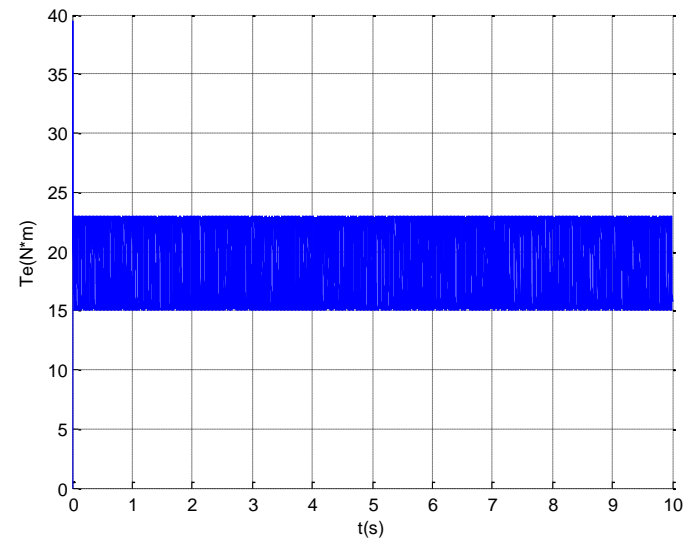

(d) The torque response of traditional DTC

Figure 6. Simulation results

\section{CONCLUSIONS}

In this paper, the fuzzy neural network is trained by using the fuzzy neural network algorithm automatic generation, adjustment of membership function and fuzzy rule. By the study of network parameter and structure, the model of DTC system is constructed. The simulation results of fuzzy neural network and traditional DTC system demonstrate the effectiveness of the application of fuzzy neural network on DTC system under low-speed, solving the problem in traditional DTC system under lowspeed.

\section{REFERENCES}

[1] Li Xinyu, Ma Mingzhi and Liao Yanpei, "Research on Direct Torque Control for Asynchronous Machine," Power Science and Engineering, vol. 29, Jul. 2013, pp.27-32.

[2] Lin Qi, Zhao Liang and Li Zhiqiang, Summatize of SpeedSensorless Science \& Technology Information, vol. 44, Oct. 2010, pp.16 19.

[3] Fang Jing, "Design of DTC system based on Fuzzy Neural Network, " Journal of Ningbo Polytechnic, vol. 32, Feb. 2010, pp. 19-21.

[4] Guo Zhongling, Wang Jun, "Research on Double-Fuzzy Direct Torque Control System, " Small \& Special electrical machines, vol. 8, Jan. 2010, pp. 62-69.

[5] Gu Deying, Ji Zhengjun and Zhang Ping, "Modeling and Simulation of Asynchronous Motors based on Simulink," Proceedings of the Chinese Society of Universities for Electric Power System and Automation, vol. 15, Feb. 2003, pp. 71-73.

[6] Li Jiayu, Xv Zhong and Chao Kaiyu, "Test O-line of the Stator Resistance Using Artificial Neural Network," Machinery Design \& Manufacture, vol. 20, April. 2003, pp. 44-46.

[7] Li Xiaofan, "Research on Speed Sensor-less DTC System of Genetic Neura 1 Network," Journal of Yancheng Institute of Technology(Natural Science Edition), vol. 22, Mar. 2009, pp.47-50.

[8] Xie Liang and Nv Yongjian, "Permanent Magnet Synchronous Motor Direct Torque Control Based on Modified Flux Error Algorithm," Small \& Special Electrical Machine, vol. 59, Aug. 2010, pp.59-61.

[9] Hong Naigang, "Matlab Simulation of Power Electronics and Power Drive," China Machine Press, 2006.

[10] Chang Xiaoying and Huang Huiying, "Simulation of Direct Torque Control System for Asynchronous Motor," Journal of Henan Normal University (Natural Science), vol. 39, Jun. 2011, pp.59-62. 